\title{
Distribution of glutamic acid decarboxylase immunoreactivity within the brain of oval squid Sepioteuthis lessoniana
}

\author{
Shiori Kobayashi ${ }^{1}$, Chitoshi Takayama ${ }^{2}$, Yuzuru Ikeda ${ }^{1, *}$ \\ ${ }^{1}$ Department of Marine and Environmental Sciences, Graduate School of Engineering and Science, \\ and ${ }^{2}$ Department of Molecular Anatomy, Graduate School of Medicine, University of the Ryukyus, Okinawa 903-0213, Japan
}

ABSTRACT: Coleoid cephalopods (squid, cuttlefish, and octopus) have the largest and most complex brains of all invertebrates and show behavioral abilities similar to those of vertebrates. Among the coleoids, the oval squid Sepioteuthis lessoniana forms well-structured schools that are indicative of sociality. These behaviors are reflected in aspects of the well-developed brain. In this study, we focused on the role of the cephalopod brain in complex behavior. In order to reveal the network of $\gamma$-aminobutyric acid (GABA) in coleoids, we examined the immunohistochemical localization of glutamic acid decarboxylase (GAD), which is the synthetic enzyme of GABA, in the brain of young $S$. lessoniana. We found that GABAergic neurons and their axons were distributed throughout the brain. GABA neurons were abundantly localized in the inferior frontal lobe, which is involved in controlling arm motions, and in the subesophageal masses, which are lower and intermediate centers of action. GABAergic fibers were abundantly localized in the tract that runs from the superior frontal lobe to the vertical lobe. These results suggested the involvement of GABA in both cognitive behaviors (such as learning and memory) and in movement.

KEY WORDS: Glutamic acid decarboxylase . Neurotransmitter · Brain · Oval squid · GABA · $\gamma$-aminobutyric acid

*Corresponding author. Email: ikeda@sci.u-ryukyu.ac.jp

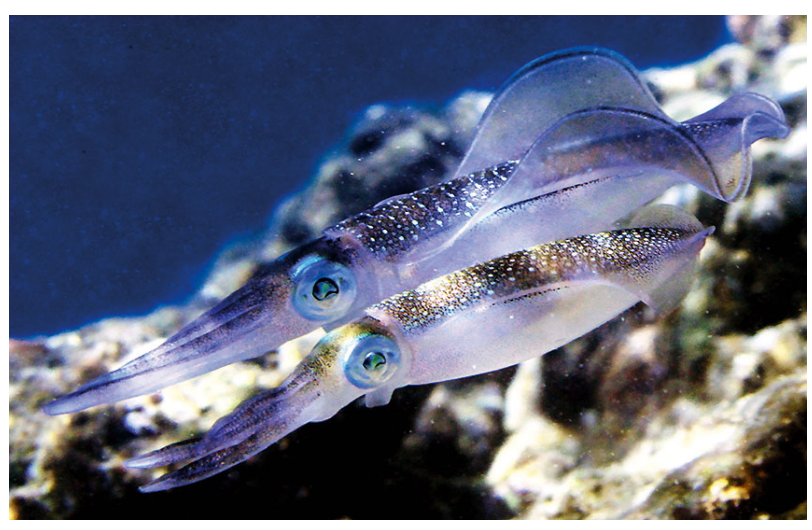

Oval squid Sepioteuthis lessoniana demonstrating social behaviour.

Photo: Ryuta Nakajima

\section{INTRODUCTION}

The coleoid cephalopod mollusks (squid, cuttlefish, and octopus) have elaborate sense organs and central nervous systems (CNS) that are the most complex among invertebrates (Budelmann 1995). The relative volume of the coleoid cephalopod CNS is larger than that of phylogenetically lower vertebrates such as fishes and reptiles, but smaller than that of higher vertebrates such as mammals and birds (Packard 1972). The complex and large CNS enables these animals to adapt to various oceanic environments. Cephalopods are competitive counterparts of fish,

(C) The authors 2013. Open Access under Creative Commons by Attribution Licence. Use, distribution and reproduction are unrestricted. Authors and original publication must be credited. 
and live in various types of marine environments where they are active predators and migrators, capable of moving quickly. Cephalopods' remarkable behavioral and cognitive abilities include learning processes (e.g. reversal, observational, and spatial learning) that are equivalent to those observed in many vertebrates (Hanlon \& Messenger 1996). In spite of their short lifespan (from 1 to 2 yr) cephalopods are equipped with major sense organs, including human-like lens eyes. These advanced features are considered to be a consequence of coevolution with their rivals - marine vertebrates such as fish (Packard 1972). Considering these characteristics, the cephalopod brain has been the subject of many investigations of brain mechanisms that underlie behavioral plasticity (Hochner et al. 2006).

The oval squid Sepioteuthis lessoniana is a nektonic animal that is widely distributed throughout the shallow waters of the Indian and West Atlantic Oceans. Oval squid have 2 specific behavioral characteristics that other cephalopods do not have. One of these unique characteristics is that they form a well-structured school. It has been reported that the Caribbean reef squid, $S$. sepioidea, which is phylogenetically close to $S$. lessoniana, exhibits social interactions within shoals in which each member is arranged in a definite order with one individual acting as a sentinel (Moynihan \& Rodaniche 1982). A similar type of schooling behavior appears in S. lessoniana up to 2 months after hatching, at which age squids are thought to become capable of recognizing schoolmates (Sugimoto \& Ikeda 2012). The second characteristic unique to the oval squid is the capacity to change its body color (termed 'body pattern') very quickly. Body patterns are involved in many aspects of coleoid life, including courtship, communication, camouflage, and predator-prey relationships (Hanlon \& Messenger 1996). These characteristics indicate the possibility that $S$. lessoniana have sociality. Previous studies have demonstrated the cytoarchitecture of the CNS of adult and embryonic squids and paralarvae (Meister 1972, Young 1974, 1976, 1977, 1979, Messenger 1979, Marthy 1987, Shigeno et al. 2001a,b, Shigeno \& Yamamoto 2002, Kobayashi et al. 2013). Although some biochemical and immunohistochemical studies have identified the main neurotransmitters and neuromodulators present in the cephalopod brain (Tansey 1979, Messenger 1996), little is known about the neuronal mechanisms that underlie these complex behaviors in $S$. lessoniana.

To reveal the functional network in the CNS that underlies brain functions linked to complex behaviors, we focused on one of the major neurotransmitters in the CNS: $\gamma$-aminobutyric acid (GABA). GABA is the major inhibitory neurotransmitter in both vertebrates and invertebrates (Jackson et al. 1990, Lunt 1991, Nishimura et al. 2008), and is highly conserved in evolution; it has been suggested that GABA plays a role in various higher functions in the brain of the common cuttlefish Sepia officinalis and common octopus Octopus vulgaris (Tsukada et al. 1964, Cornwell et al. 1993, D'Aniello et al. 1995). In adult vertebrates, GABAergic neurons play important roles in a variety of states and physiological processes, including inhibition of anxiety, walking, circadian rhythms, and emotional responses (Stork et al. 2000, Miczek et al. 2002). Physiological and pharmacological studies have reported that GABA is both excitatory and inhibitory for neurons in the CNS and is involved in activating feeding movements via buccal and cerebral ganglion neurons in mollusks (Cooke \& Gelperin 1988, Richmond et al. 1991, 1994, Arshavsky et al. 1993, Hernádi 1994, Hatakeyama \& Ito 2000, Elliott \& Susswein 2002). The presence of GABA was investigated in cephalopods by Tansey (1979) and Cornwell et al. (1993), and conflicting evidence has been presented regarding the presence of GABA in the cephalopod CNS (Tansey 1979). Cornwell et al. (1993) demonstrated widespread GABA-like staining in the many brain lobes of the Eledone. In the present study, we re-examined the existence and distribution of GABAergic elements in the CNS of Sepioteuthis lessoniana. To detect the GABAergic system, we performed immunohistochemistry for glutamic acid decarboxylase (GAD), which is the synthetic enzyme of GABA and a marker protein of GABA neurons in young squid.

\section{MATERIALS AND METHODS}

\section{Egg collection and rearing of paralarvae}

Egg capsules of Sepioteuthis lessoniana spawned on set nets were collected from Nago Bay of the Okinawa Islands, Okinawa, Japan. The egg capsules were transferred to the laboratory at the Department of Biology, Chemistry and Marine Sciences in the University of the Ryukyus, as described in a previous study (Kobayashi et al. 2013). These egg capsules were maintained in a $180 \mathrm{l}$ circular polystyrene tank consisting of a closed seawater system (OPEN-FIELD tank, Aqua, $726 \times 1065 \times 303 \mathrm{~mm}$, 60 l filtration tank with a condenser and sterilizer). Hatchlings were isolated in a $20 \mathrm{l}$ circular tank consisting of a closed seawater system (Multi-hydense ${ }^{\circledR}$ Aqua, $300 \mathrm{~mm}$ diameter, $180 \mathrm{l}$ filtration tank) and reared for 100 to 
$112 \mathrm{~d}$. The date on which the largest number of squid hatched was defined as Day Zero. Water temperature was maintained between 24.0 and $25.0^{\circ} \mathrm{C}$ throughout the experiment. Salinity was adjusted to approx. 35 and $\mathrm{pH}$ was maintained above 7.8. Water quality and environmental factors were as follows: temperature 24.1 to $24.7^{\circ} \mathrm{C}$; salinity 34.0 to 36.5 ; $\mathrm{pH} 7.53$ to 8.1 (pH was $>7.8$ during the majority of the experiment). Squid $<14$ d old were fed live prey (adult mysids Neomysis japonica, guppy fry Poecilia reticulata, nauplii of brine shrimp Artemia salina). Squid $>14 \mathrm{~d}$ old were fed frozen organisms (sakura shrimp Sergia lucens, anchovy Engraulis japonicus, common prawn Palaemon paucidens) 3 times per day. New hatchlings were fed 4 times per day at approx. the same time each day.

\section{Animals}

Five young male Sepioteuthis lessoniana (100 to $112 \mathrm{~d}$ old) reared in captivity were used in this study. The dorsal mantle length and wet body weight of the squid were in the ranges of 61.2 to $93.1 \mathrm{~mm}$ and 32.5 to $53.6 \mathrm{~g}$, respectively. According to criteria reported by Segawa (1987), the stage of all animals used in this investigation was 'young 2,' and the shape of their bodies was nearly identical to that of adults.

\section{Tissue preparation}

All animals were anesthetized in 2\% ethanol in seawater, after which dorsal mantle length (ML) and wet body weight (BW) were measured. The animals were then killed by decapitation, and the brains were rapidly removed and fixed in 10\% neutralized formaldehyde in seawater $(\mathrm{pH}$ 7.4). Brains were dehydrated using a graded series of ethanol, and were then embedded in paraffin wax. The paraffin blocks were cut into $10 \mu \mathrm{m}$ thick sagittal sections, and the sections were mounted on glass slides pre-coated with silane.

\section{Immunohistochemistry}

After removing the paraffin in xylene and the graded series of ethanol, sections were treated with $3 \%$ normal goat serum in phosphate buffer ( $\mathrm{PB}, 0.1 \mathrm{M}, \mathrm{pH} 7.4$ ) for $30 \mathrm{~min}$, and were reacted in the antiserum against GAD 65 and 67 (diluted to 1:2000, AB1511, MilliporeChemicon) overnight at room temperature. Sections were rinsed 3 times with PB for 10 min, visualized using the avidin-biotin-peroxidase complex (ABC) method, and counter-stained by hematoxylin. We discriminated immunostaining and hematoxylin by the obtained colors - purple for hematoxylin and brown for immunostaining. The specificity of the immunoreaction was checked by the antibody-absorption test using GAD antigen peptide (GAD, control peptide for AB1511, Millipore-Chemicon). Primary antibody was added to the antigen peptide $(10 \mu \mathrm{g}$ per $\mathrm{m}$ of diluted antibody). No specific staining was obtained.

\section{Analysis}

We measured the relative densities of GAD-positive cell bodies in each lobe from light micrographs using Image $\mathrm{J}^{\circledR}$, as previously reported (Bardou et al. 2009). The density of GAD-positive fibers was determined by converting the intensity of gray in photographs of sagittal sections into grayscale using Adobe Photoshop ${ }^{\circledR}$ CS.

\section{RESULTS}

\section{General structure of oval squid CNS}

We identified the structure of the Sepioteuthis lessoniana CNS according to previous reports using the same species (Shigeno et al. 2001b) and the squids Loligo pealeii and L. vulgaris (Young 1974, $1976,1977,1979$, Nixon \& Young 2003). The CNS of S. lessoniana, consisting of an optic lobe and central cerebral mass, is located between the eyes (Fig. 1A). As in other modern cephalopods, the central mass surrounds the esophagus and is divided into the supra- and subesophageal masses by the esophagus (Fig. 1B). The central mass consists of several lobes; these lobes are the basic unit of invertebrate organization and consist of an outer cell body layer and an inner neuropil layer containing dendrites, axons, and synapses (Fig. 1B, Young 1974, 1976, 1977, 1979, Messenger 1979, Hochner et al. 2006). The neural pathways in the CNS are shown in Fig. 1C,D.

\section{Localization of GAD-positive neurons}

GAD-positive neurons were detected throughout the brain of the oval squid. The relative densities of GAD-positive cell bodies in each lobe are summarized in Fig. 2 and Table 1. Many GAD-positive neu- 

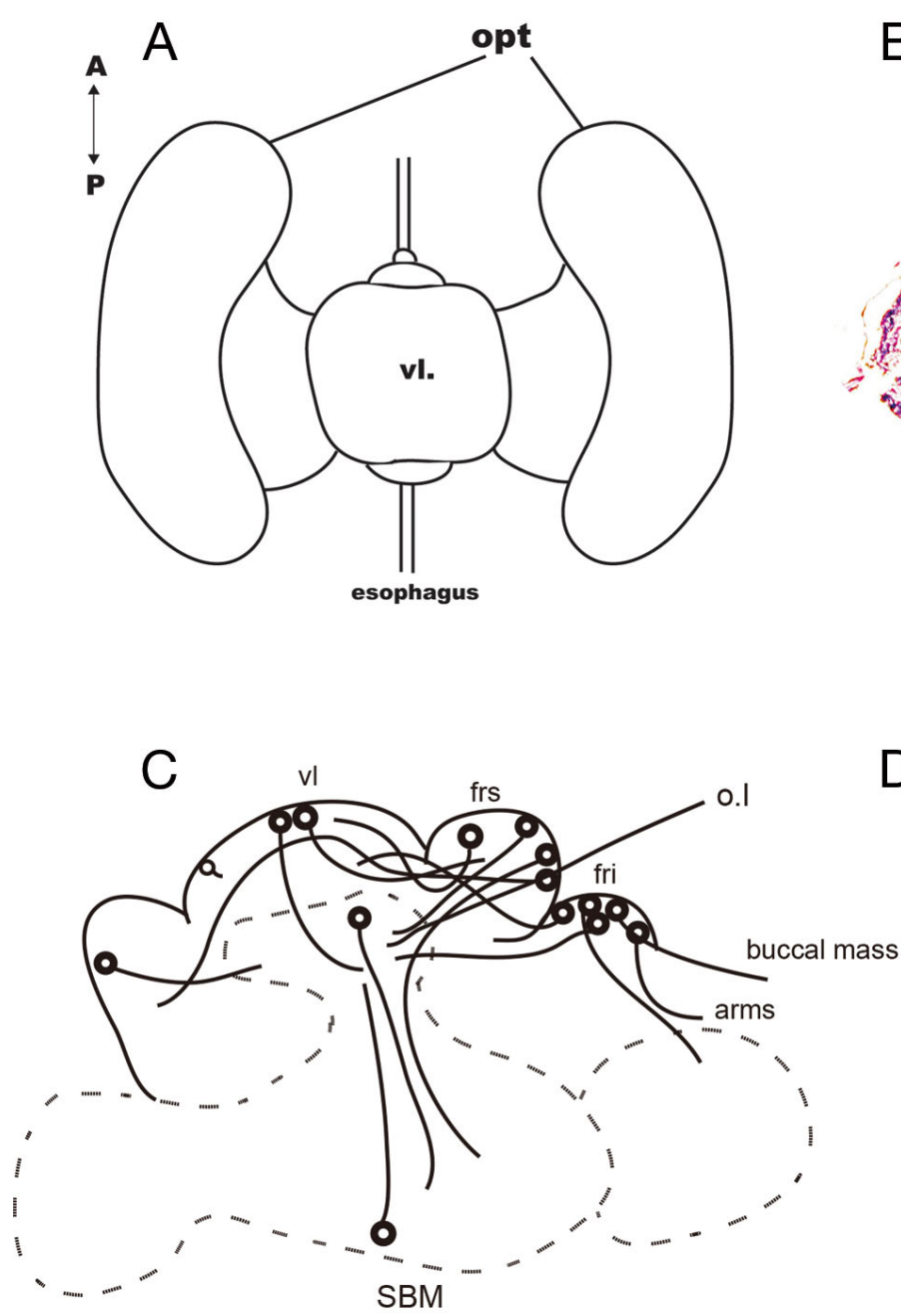
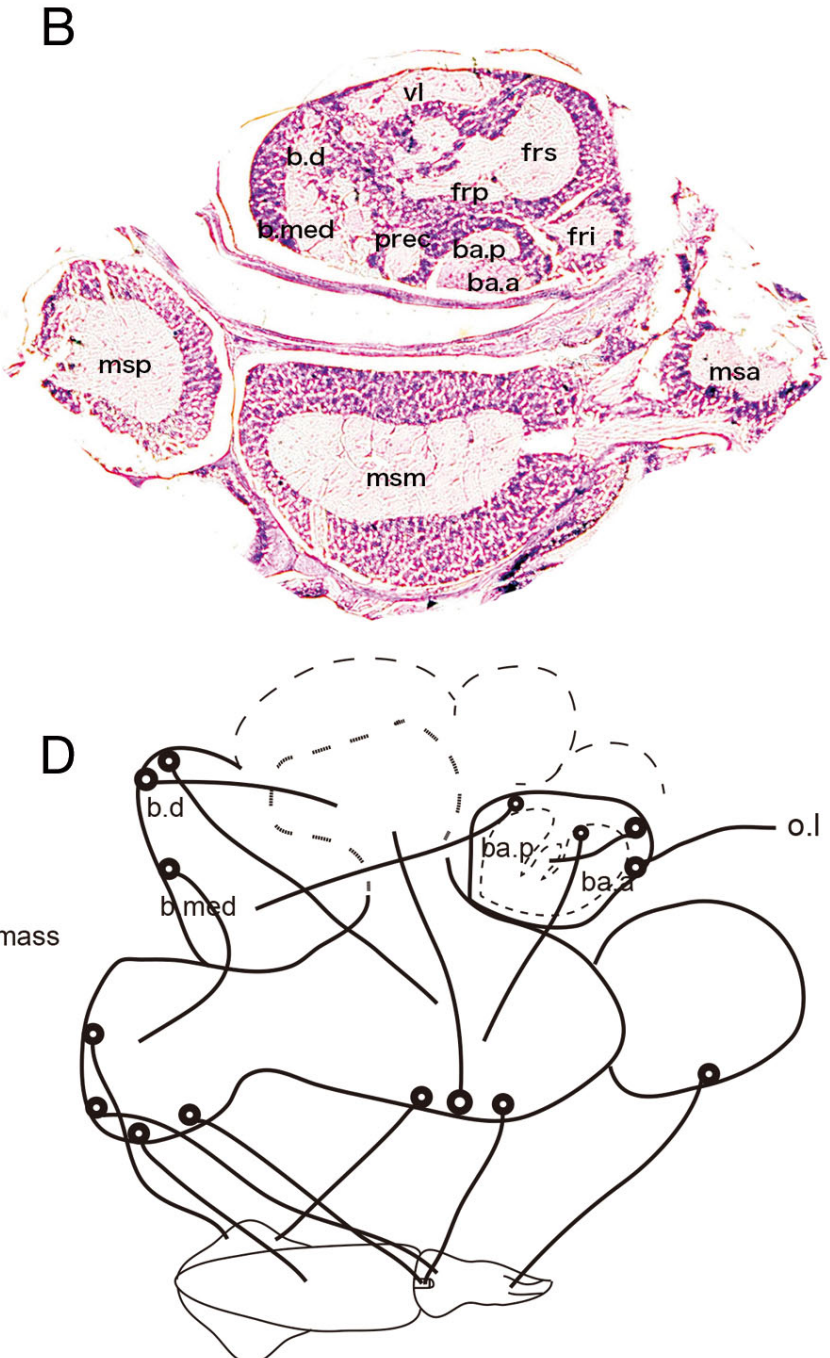

Fig. 1. Central nervous system Sepioteuthis lessoniana. (A) Dorsal view. (B) Photomicrograph of sagittal section (HE staining). (C) Main pathway in the vertical lobe system. The input and output of the vertical lobe go back and forth to the superior frontal and the subvertical lobes. The subvertical lobe is the main output from the vertical lobe system to the optic lobes and to the other centers. The input to the subvertical lobe comes from the vertical system, the optic lobe, the dorsal basal lobe, and the subesophageal mass. The anterior-superior frontal lobe sends fibers to the subvertical lobe and the subesophageal mass. The posterior-superior frontal lobe contains numerous small cells running to the vertical lobe. The inferior frontal lobe serves as a main output and input between arms and lips and the vertical lobe system. (D) Main pathway in the basal lobe system and the subesophageal mass. The anterior-anterior basal lobe is further divided into the lateral part, which contains large efferent cells with axons running to the oculomotor and other subesophageal motor centers, and the antero-median lobule, which sends axons back to the optic lobes and the parallel fiber region. The subesophageal mass contains motor neurons that run to the muscles of locomotors. A: anterior; P: posterior; opt: optic lobe; vl: vertical lobe; frs: superior frontal lobe; fri: inferior frontal lobe; frp: post-frontal lobe; prec: precommissural lobe; ba.a: anterior-anterior basal lobe; ba.p: posterior-anterior basal lobe; b.d: dorsal basal lobe; b.med: median basal lobe; msa: anterior subesophageal mass; msm: middle subesophageal mass; msp: posterior subesophageal mass; o.l: optic lobe; SBM: subesophageal mass

rons were distributed evenly in the subesophageal mass. In contrast, the distribution of GAD-positive neurons was not equal in the supraesophageal mass, where the highest density was detected in the inferior frontal lobe. GAD-positive neurons were also abundant in the neuropil layer of the inferior frontal lobe, subvertical lobe, antero-median lobule, and subesophageal mass. No GAD-positive neurons were detected in the superior frontal lobe. Largesized GAD neurons (26 to $80 \mu \mathrm{m}$ diameter) were detected in the subesophageal mass and around the tract, connecting the precommissural lobe and the inferior frontal lobe. Other GAD-positive neurons were in the size range of 10 to $30 \mu \mathrm{m}$ diameter All animals had a similar distribution of GAD-positive neurons. 

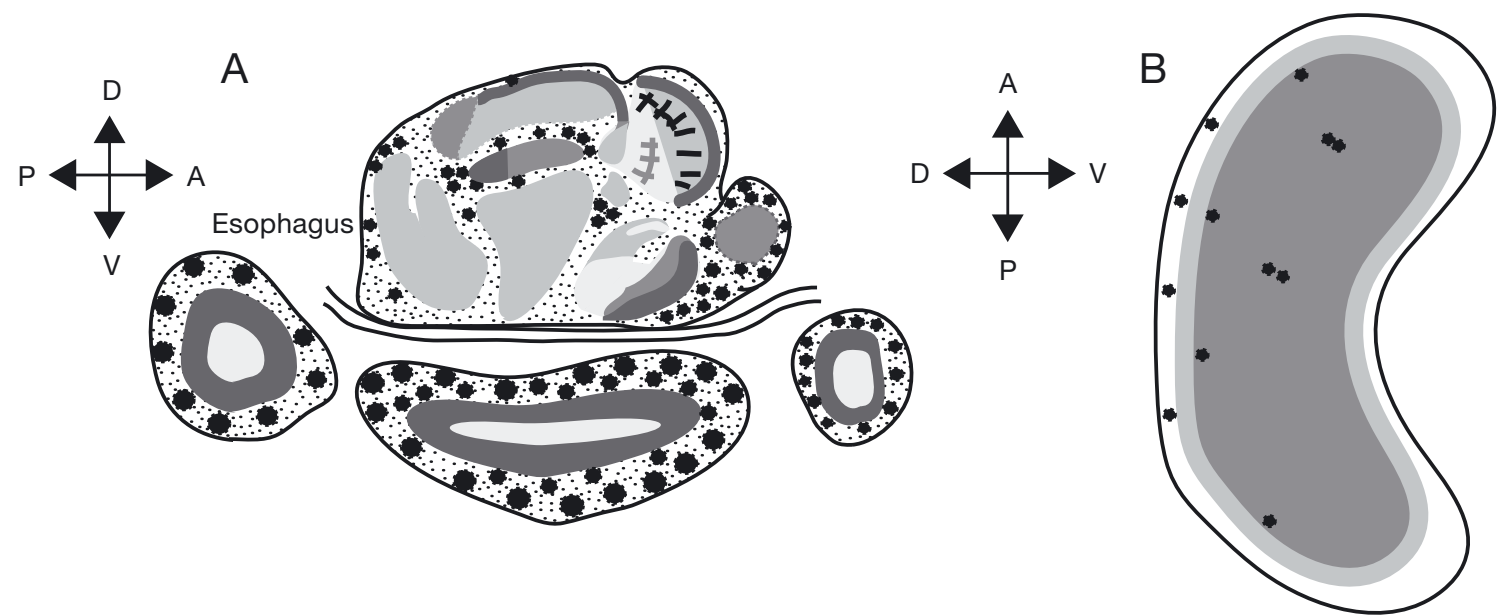

Fig. 2. Sepioteuthis lessoniana. Schematic outline of the distribution of GABAergic elements in the brain. A: anterior, P: posterior, D: dorsal, V: ventral. (A) Sagittal section, GAD immunoreactive elements in the central mass of the brain; and (B) sagittal section, GAD immunoreactive elements in the optic lobes. GAD-positive neurons (black dots) are plotted on the CNS with respect to their relative abundance and distribution. Their sizes are proportional to the size of immunoreactive cell bodies

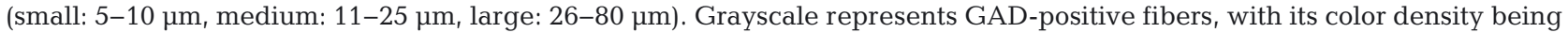
proportional to the number of immunoreactive elements

Table 1. Sepioteuthis lessoniana. Distribution and relative abundance of GADpositive cell bodies and fibers within the CNS (-: no detected staining $;+$ : sparse positive staining $;++$ : moderate positive staining ${ }_{i}+++$ : high positive staining, +++ : extensive positive staining)

\begin{tabular}{|c|c|c|c|}
\hline \multicolumn{2}{|l|}{ Brain region } & Cell bodies & \multirow[t]{2}{*}{ Fibers } \\
\hline \multirow{2}{*}{\multicolumn{4}{|c|}{ Supraesophageal lobes }} \\
\hline \multicolumn{3}{|l|}{ Vertical lobe complex } & \\
\hline \multirow[t]{2}{*}{ Vertical lobe } & Central part & + & ++ \\
\hline & Peripheral part & + & +++ \\
\hline Inferior frontal lobe & & ++++ & +++ \\
\hline \multirow[t]{2}{*}{ Superior frontal lobe } & Anterior-superior frontal & - & ++++ \\
\hline & Posterior-superior frontal & - & +++ \\
\hline Post-frontal lobe & & + & ++ \\
\hline \multirow[t]{2}{*}{ Subvertical lobe } & Anterior subvertical lobe & +++ & +++ \\
\hline & Posterior subvertical lobe & ++ & +++ \\
\hline \multirow{2}{*}{\multicolumn{4}{|c|}{ Basal lobes }} \\
\hline & & & \\
\hline \multicolumn{4}{|l|}{ Anterior basal lobe } \\
\hline \multirow[t]{3}{*}{ Anterior-anterior basal lobe } & Lateral part & + & ++++ \\
\hline & Antero-median lobule & +++ & - \\
\hline & Spine & - & + \\
\hline \multirow[t]{2}{*}{ Posterior-anterior basal lobe } & Spine & - & + \\
\hline & Lateral part & - & ++ \\
\hline \multicolumn{4}{|l|}{ Posterior basal lobe } \\
\hline Dorsal basal lobe & & ++ & ++ \\
\hline Median basal lobe & & ++ & ++ \\
\hline Subpedunculate lobe 1 & & ++ & ++ \\
\hline Subpedunculate lobe 2 & & + & ++ \\
\hline Subpedunculate lobe 3 & & + & ++ \\
\hline \multicolumn{4}{|l|}{ Subesophageal lobes } \\
\hline Anterior subesophageal mass & & ++++ & ++++ \\
\hline Middle subesophageal mass & & ++++ & ++++ \\
\hline Posterior subesophageal mass & & ++++ & ++++ \\
\hline \multicolumn{4}{|l|}{ Optic lobes } \\
\hline \multicolumn{4}{|l|}{ Cortex } \\
\hline Outer granule cell layer & & + & - \\
\hline Inner granule cell layer & & + & - \\
\hline Plexiform layer & & - & ++ \\
\hline Medulla & & + & +++ \\
\hline MSFtract & & - & ++++ \\
\hline
\end{tabular}

\section{Localization of GAD-positive fibers}

GAD-positive fibers ran through all lobes of the Sepioteuthis lessoniana brain, but with unequal intensity. The ranges of GAD-positive fibers in each lobe are summarized in Fig. 2 and Table 1. In the subesophageal mass, many GAD-positive fibers were distributed equally in each region. In contrast, the distribution of GAD-positive fibers was not equal in the supraesophageal mass. In particular, GAD-positive fibers were abundant, with high density, in the tract that exhibited a matrix-like formation of afferent fibers connecting between the superior frontal lobe (input) and the vertical lobe (output) (MSF tract) (Young 1971, Hochner et al. 2003, 2006, Shomrat et al. 2010). Among 5 animals used in this study, there was no variation in the distribution of GAD-positive fibers between animals.

\section{Supraesophageal mass: vertical lobe complex}

The vertical lobe complex consists of vertical, subvertical, superior frontal, inferior frontal, post-frontal, and 
precommissural lobes (Fig. 1C, Young 1979) and has been implicated in learning ability and memory (Sanders \& Young 1940, Young 1965, Dickel et al. 1997, Nixon \& Young 2003). In the vertical lobe complex we detected numerous GAD-positive neurons in the subvertical and the inferior frontal lobes; GAD-positive neurons were not localized in the superior frontal lobe. GAD-positive fibers were scattered throughout all lobes of this complex.

Vertical lobe. This lobe is divided into 2 sections: the central and peripheral parts (Fig. 2A). The central part is covered by a monolayer of large neurons, whereas the posterior part is covered by a thick cell layer containing numerous small amacrine cells and a few large cells (Young 1979).

GAD-positive neurons were detected in central and peripheral parts of the vertical lobe. Their diameter was 10 to $20 \mu \mathrm{m}$, larger than that of amacrine cells (Figs. 3B,C). GAD-positive fibers were detected throughout the neuropil layer in the vertical lobe and were more abundant in the peripheral part than in the central part. In the central part, GAD-positive fibers ran into the neuropil from the dorsal to the ventral direction. Many granular GAD-positive elements and GADpositive fibers were distributed in the peripheral part.

Subvertical lobe. This lobe is localized under the vertical lobe (Fig. 1B), is continuous with the precommissural lobe, and is divided into 2 parts: anterior and posterior. GAD-positive fibers were more abundant in the posterior than in the anterior part and GAD-positive neurons were scattered throughout the cell layer of this lobe. In the dorsal side of the cell layer of the anterior subvertical lobe, GAD-positive neurons lay in 1 or 2 rows (Fig. 3F). The size of these neurons varied from 10 to $30 \mu \mathrm{m}$ in diameter. GAD-positive neurons were gathered in the cell layer of the posterior subvertical lobe, and the size of these neurons was almost uniform (approximately $20 \mu \mathrm{m}$ diam.). The axons of GAD-positive fibers ran into the neuropil of the subvertical lobe.
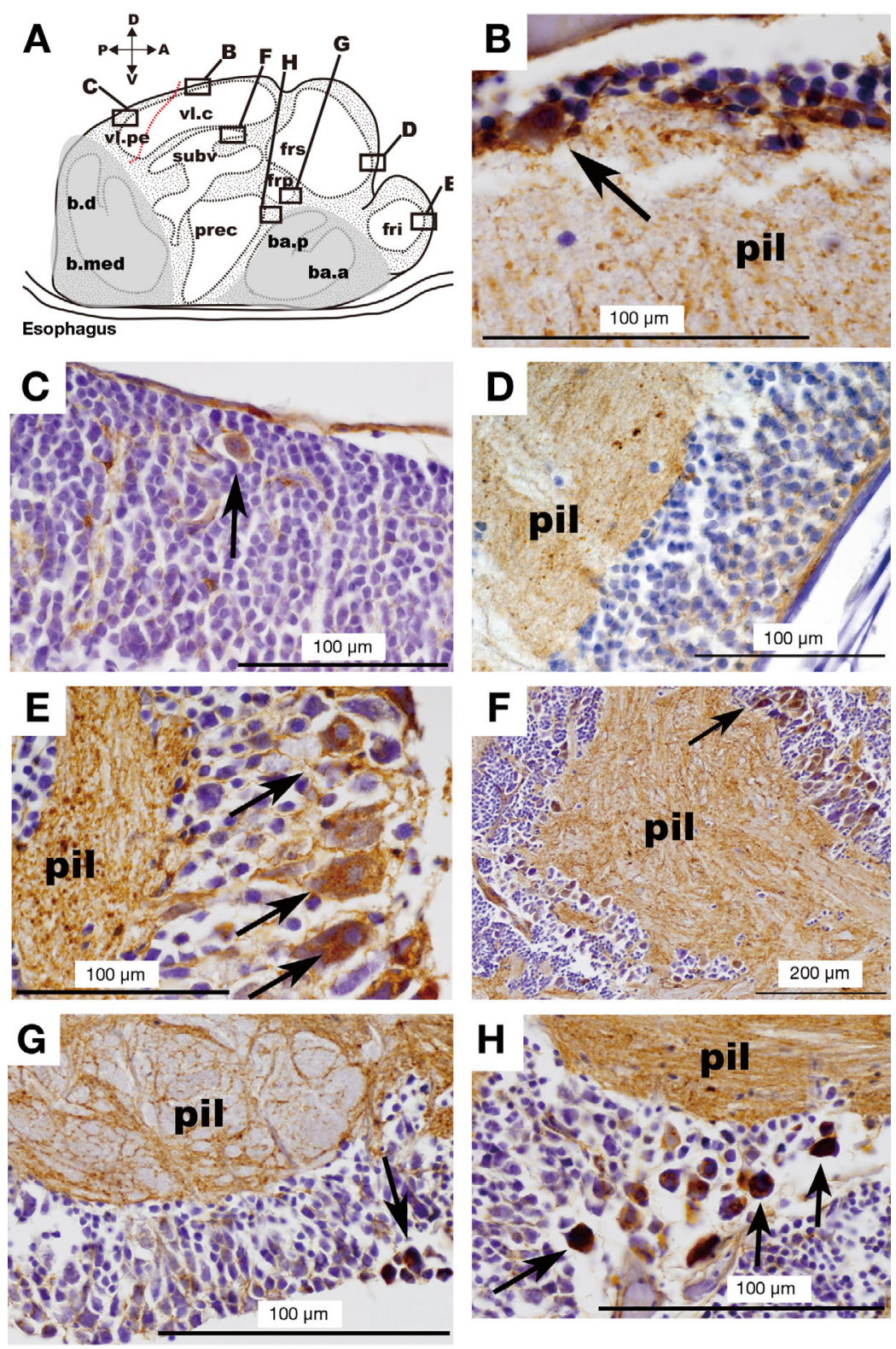

Fig. 3. Sepioteuthis lessoniana. GAD immunoreactive elements within the vertical lobe complex of the brain (pil: neuropil). (A) Schematic drawing of sagittal section of the vertical lobe complex; see Fig. 1; (B) central part of the vertical lobe; $(C)$ peripheral part of the vertical lobe; (D) superior frontal lobe; $(E)$ inferior frontal lobe; $(F)$ anterior subvertical lobe; $(\mathrm{G})$ post-frontal lobe; and $(\mathrm{H})$ around the tract of precommissural and inferior frontal lobes (neuropil on the picture is the post-frontal lobe). Arrows point to GAD immunoreactive cell bodies

Superior frontal lobe. The superior frontal lobe is divided into 2 parts, anterior and posterior (Fig. 1C). GAD-positive fibers were detected in both the anterior and posterior parts, and ran through the neurons of the outer cell body layer. The interweaving plexus of the posterior-superior frontal lobe in particular contained a greater abundance of GAD-positive fibers. However, there were no GABAergic neurons 
in either the anterior- or the posteriorsuperior frontal lobes (Fig. 3D).

Inferior frontal lobe. The inferior frontal lobe is located at the most anterior part of the supraesophageal mass (Fig. 1C). In the inferior frontal lobe, GAD-positive fibers were abundantly observed in the neuropil, and these fibers diverged in various directions. GAD-positive dots were clustered in high density. GAD-positive neurons, the diameter of which ranged from 10 to $30 \mu \mathrm{m}$, were detected in superficial parts of the cell layer (Fig. 3E). Axons of these neurons did not project into the neuropil of the inferior frontal lobe, and ran in various directions. The density of GABA neurons was highest in the supraesophageal mass.

Post-frontal lobe. The post-frontal lobe is a set of cells grouped around the superior frontal lobe (Fig. 1B, Nixon \& Young 2003). Few GAD-positive cell bodies were found (Fig. 3G; 10 to $15 \mu \mathrm{m}$ diameter) and GAD-positive fibers were scattered in this lobe.

\section{Supraesophageal mass: basal lobes}

The basal lobes are higher motor centers that may control movements, and are divided into an anterior and a posterior region (Fig. 1B, Boycott 1961).

Anterior basal lobe. The anterior basal lobe consists of 2 lobes: the anterior-anterior basal lobe and the posterior-anterior basal lobe (Fig. 1B) GADpositive neurons were most abundant in the antero-median lobule. There were few GAD-positive neurons in the other parts of the anterior basal lobes. The abundance of GAD-positive fibers was unequal among regions.

Anterior-anterior basal lobe. The anterior-anterior basal lobe is further divided into the lateral part and the antero-median lobule (Fig. 4A, Young 1977). Numerous GAD-positive neurons (10 to $35 \mu \mathrm{m}$ diam.) were detected in the antero-median lobule that sends axons to the optic lobe (Fig. 4B), and a few GAD-positive neurons (10 to $15 \mu \mathrm{m}$ diameter) were detected in the lateral part (Fig. 4C). In the neuropil of the lateral part, we found 2 layers of GAD-pos-
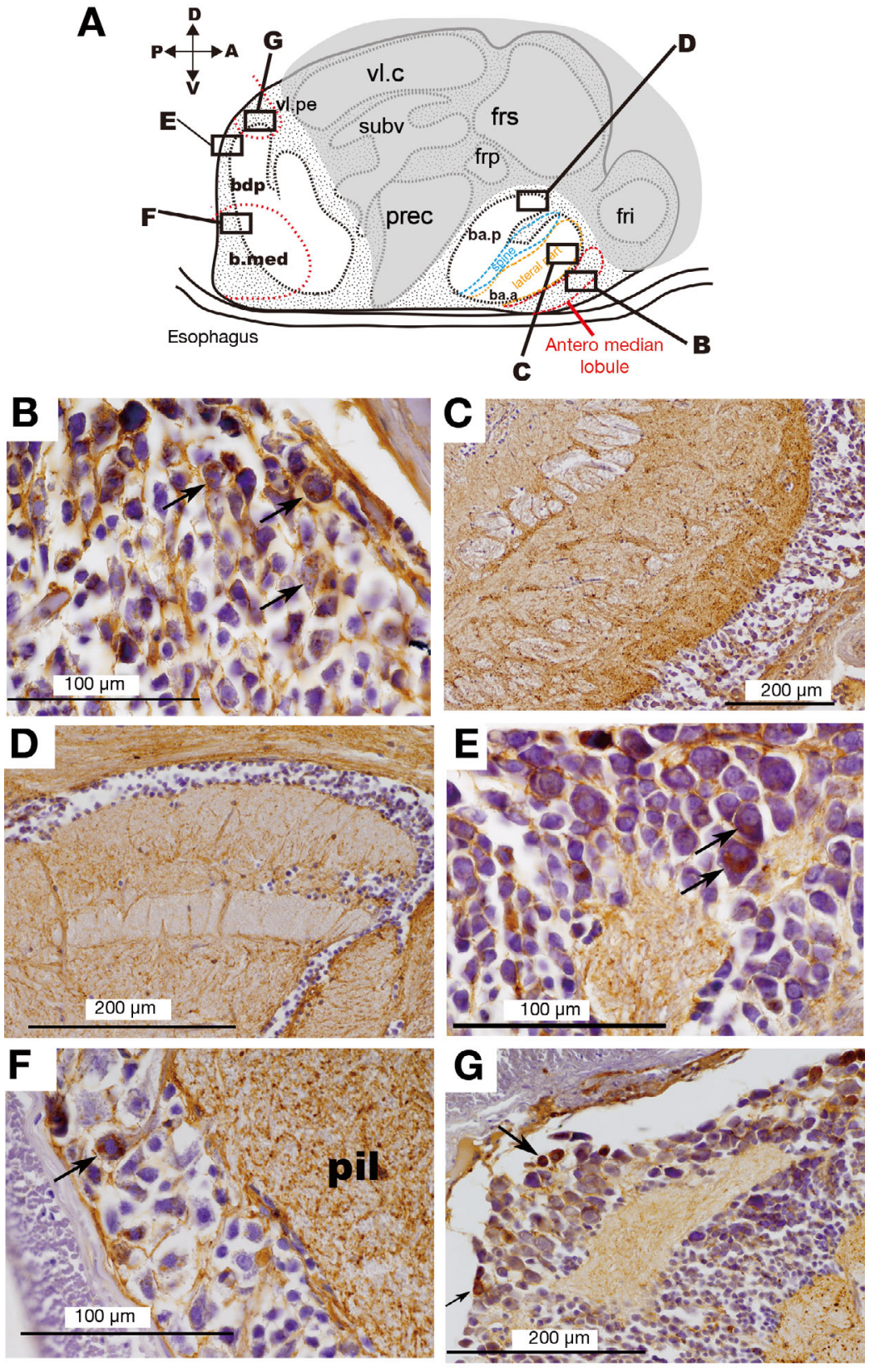

Fig. 4. Sepioteuthis lessoniana. GAD immunoreactive elements within the basal lobes of the brain (pil: neuropil). (A) Schematic drawing of sagittal section of the basal lobes; (B) antero-median lobule; (C) lateral part and the spine of the anterior anterior lobe; (D) spine of the posterior anterior lobe; $(E)$ posterior part of the dorsal basal lobe; (F) median basal lobe; and (G) subpedunculate lobe 1. Arrows point to GAD immunoreactive cell bodies

itive fibers (Fig. 4C). These fibers ran in an anteriorposterior (tangential) direction (Fig. 4C). One layer on the anterior side of the neuropil contained abundant GAD-positive fibers, while a different layer contained few fibers. GAD-positive fibers were scarce in the spine region (Fig. 4C). However, some tracts of GAD-positive fibers ran parallel between the anterior-anterior and anterior-posterior lobes (Fig. 4C). 
Posterior-anterior basal lobe. The posterior anterior basal lobe is divided into the spine region and the lateral part (Young 1977). GAD-positive neurons were not detected in the spine region, and GAD-positive fibers were few. The lateral part of the posterioranterior basal lobe contained many GAD-positive fibers (Fig. 4D), but relative to other lobes their numbers were low. The lateral part of this lobe did not contain GAD-positive neurons.

Posterior basal lobe. The posterior basal lobe is located at the back of the supraesophageal mass (Fig. 1B), and is divided into the dorsal basal, median basal, lateral basal and subpedunculate lobes (Young 1977). We identified the dorsal basal, median basal and subpedunculate lobes.

Dorsal basal lobe. This lobe is one of the least understood parts of the cephalopod brain and is thought to control actions of defense and avoidance (Nixon \& Young 2003). GAD-positive neurons (15 to $25 \mu \mathrm{m}$ diameter) were clustered along the edge of the posterior basal region (Fig. 4E). Axons of the GAD-positive neurons ran through the neurons and projected into the neuropil layer. GAD-positive fibers were scattered in the dorsal basal lobe; their density was constant through both the anterior and posterior regions.

Median basal lobe. This lobe is located on the posterior side of the supraesophageal mass (Fig. 1C) and joins the middle subesophageal mass at the sides. Some GAD-positive neurons were detected (Fig. 4F). GAD-positive fibers were observed and their density and abundance were to the same degree as that observed in the dorsal basal lobe. Axons of these neurons projected into the neuropil of the median basal lobe (Fig. 4F).

Subpedunculate lobes. These lobes are divided into 3 regions: subpedunculate lobes 1, 2, and 3. GAD-positive neurons were mainly detected in the edge of subpedunculate lobe 1 (Fig. 4G), and few were detected in sub- pedunculate lobes 2 and 3. GAD-positive fibers were detected in each of the subpedunculate lobes.

\section{Subesophageal mass}

The subesophageal mass of coleoid cephalopods can be divided into 3 regions: the anterior, middle, and posterior subesophageal masses (Fig. 1B, Young 1976).

Anterior subesophageal mass. The anterior subesophageal mass is composed of the brachial lobe (Nixon \& Young 2003). GAD-positive fibers were detected throughout the neuropil and their intensity was strong (Fig. 5B). Many GAD-positive neurons (15 to $25 \mu$ m diameter) were detected (Fig. 5C).

Middle and posterior subesophageal masses. These masses consist of several lobes (Young 1976). Most neurons of these lobes expressed GAD, partic-
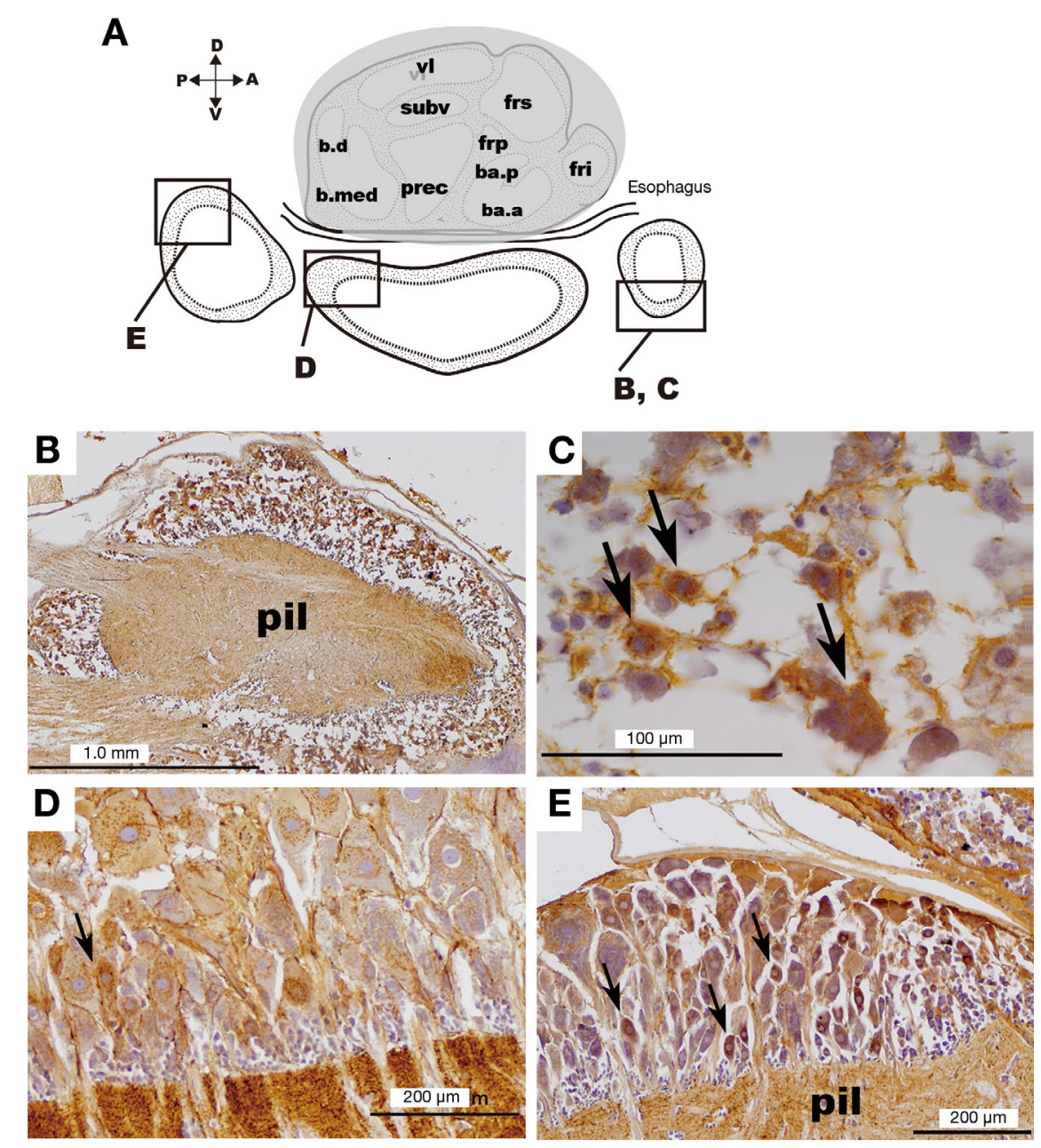

Fig. 5. Sepioteuthis lessoniana. GAD immunoreactive elements within the subesophageal mass of the brain (pil: neuropil). (A) Schematic drawing of sagittal section of the subesophageal mass, see Fig. $1 ;(B, C)$ anterior subesophageal mass; $(D)$ middle subesophageal mass; and (E) posterior subesophageal mass. Arrows point to GAD immunoreactive cell bodies 
ularly the more outer neurons (Fig. 5D,E; 15 to $80 \mu \mathrm{m}$ diam.). The axons of these neurons projected into the neuropil layer. GAD-positive fibers were detected throughout the neuropil of both masses subesophageal masses. In the outer neuropil of both masses, the intensity of GAD-positive fibers was strong compared to that of the inner neuropil.

\section{Optic lobes}

The 2 optic lobes are located on each side (laterally) of the CNS (Fig. 1A). Each optic lobe consists of 2 regions: a cortex (outer section) called the 'deep retina' and a medulla (inner section).

Cortex. The cortex primarily consists of 2 cell layers (the outer and inner granular layers). These layers are separated by a plexiform zone containing several layers of tangential fibers (Young 1974). In the outer granular layer a few GAD-positive neurons (8 to $15 \mu \mathrm{m}$ diam.) were detected (Fig. 6A), although their cell bodies were small ( 5 to $8 \mu \mathrm{m}$ diameter). A few large GAD-positive neurons (approximately $25 \mu \mathrm{m}$ diameter) were detected in the inner granular layer (Fig. 6B). GAD-positive fibers were abundant in the plexiform zone, particularly in the outer part of this zone.

Medulla. The medulla consists of many clusters of cell bodies separated by neuropils. Some GAD-positive neurons ( 8 to $15 \mu \mathrm{m}$ diameter) and fibers were detected (Fig. 6C).

\section{DISCUSSION}

\section{GABAergic neurons in the CNS}

In many lobes, GAD-positive fibers ran through the interval between neurons of the outer cell body layer in addition to the neuropil layer. These may be projection fibers, because the majority of GAD-positive neurons were medium to large in size and sent long axons toward many sources. In rat brains, the available evidence indicates that GABA is present mostly in local circuit neurons (Todd et al. 1994). However, it has been reported that GABAergic innervation of the locus coeruleus arises from the epifascicular nucleus (Ennis \& Aston-Jones 1989). The regions known to project to the supraoptic nuclei (e.g. the periventricular preoptic area and the bed nucleus of the stria terminalis) also contain GABAergic neurons (Paxinos 2004). In the striatum, major projections are GABAergic and send axons to the globus pallidus (Paxinos 2004). Kudo et al. (2012) revealed that most of the
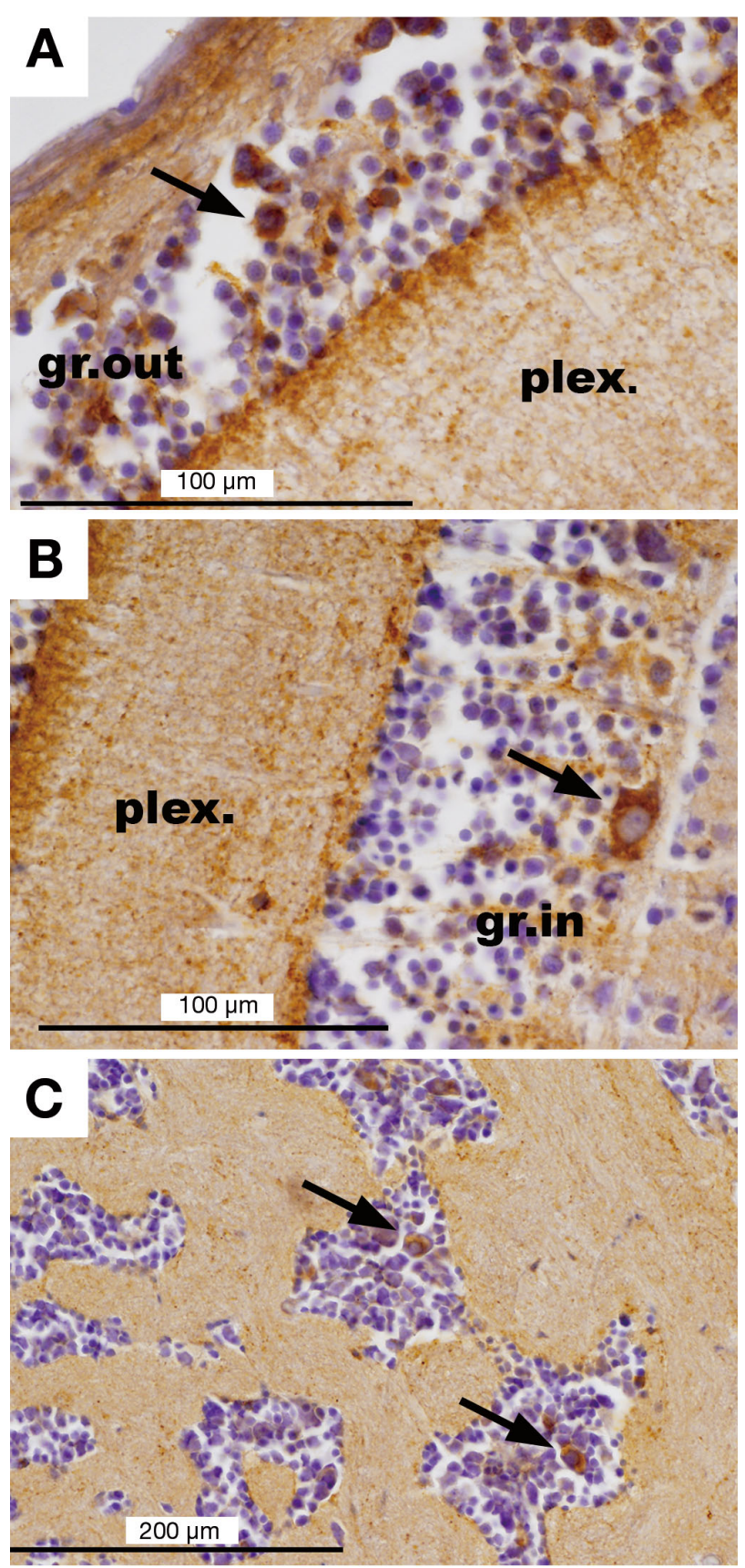

Fig. 6. Sepioteuthis lessoniana. GAD immunoreactive elements within the optic lobe of the brain. (A) Outer granular layer (gr.out) and plexiform zone (plex.); (B) inner granular layer (gr.in); and (C) medulla. Arrows point to GAD immunoreactive cell bodies

projection between the ventral tegmental area and the bed nucleus of the stria terminalis was GABAergic. Among invertebrates, neurons projecting to the lobster stomatogastric ganglion are known to be GABAergic (Cournil et al. 1990). GABA appears to have effects on the neural circuit of the Sepioteuthis lessoniana CNS. 


\section{GABAergic roles in the CNS}

\section{GABA in controlling movements}

Feeding behavior. The density of GAD-positive neurons was highest in the inferior frontal lobe. The inferior frontal lobe of squid serves as a main input and output between the arms and lips and the higher cerebral centers (Nixon \& Young 2003). Stimulation studies have revealed that the inferior frontal lobe is involved in movement of the buccal mass, progressive opening of the arms, and grasping behavior, all of which are related to feeding (Boycott 1961, Chichery \& Chichery 1991, Nixon \& Young 2003). In other mollusks (e.g. Lymnaea, Helix, Helisona, and Aplysia spp.) GABA is found in the buccal and cerebral ganglions and plays a role in activating the feeding pattern (Richmond et al. 1991, 1994, Hernádi 1994, DíazRíos et al. 1999, Hatakeyama \& Ito, 2000, Elliot \& Susswein 2002). From these reports, and because Sepioteuthis lessoniana is an active predator (Lee et al. 1994), it is suggested that GABA may be involved in feeding behavior in S. lessoniana.

Swimming behavior. Another presumed function of GABA is in controlling movement related to free swimming. GAD-positive neurons were abundant in the neuropil layer of the subvertical lobe, anteromedian lobule, and subesophageal mass. The anteromedian lobule is part of the anterior basal lobe, which functions as a higher motor center that controls and regulates intermediate and lower motor centers (Boycott 1961, Messenger 1983). Lesion experiments suggest that the anterior basal lobe inhibits fin movements (Boycott \& Young 1950, Nixon \& Young 2003), and that the anteromedian lobule causes rolling movements during acceleration (Chichery \& Chichery 1987, Nixon \& Young 2003). Furthermore, the each mass in the subesophageal mass is related to the animal movements. The anterior subesophageal mass is involved in movements of the arms and suckers (Nixon \& Young 2003). The middle subesophageal mass is the intermediate and lower motor center that controls many animal movements. The posterior subesophageal mass contains lower motor neurons to the fins and to cells involved in movements of other organs including the mantle, head, and collar. Medium- and large-sized GADpositive neurons (15 to $80 \mu \mathrm{m}$ diam.) were detected in the subesophageal mass. Past studies have described large neurons that innervated the skin, head, and arms, localized in the subesophageal mass (Young 1976, Nixon \& Young 2003). These results suggest an important role of GABAergic neurons in movement of young Sepioteuthis lessoniana. Because S. lessoniana is nektonic, controlling movements seems to be more important for them than the planktonic or benthic cephalopods such as octopus.

Body pattern. The middle and posterior subesophageal mass contain the anterior and posterior chromatophore lobes where the majority of chromatophore neuronal somata are located. GABAergic neurons and fibers were detected abundantly in these masses. Because the cephalopod skin-color system is controlled by muscles that are innervated from these neurons (Messenger 2001, Williamson \& Chrachri 2004) and Sepioteuthis lessoniana changes its complex body pattern very quickly, GABA may be involved in controlling body pattern in this species.

\section{GABA in learning and memory}

According to Bullock \& Horridge (1965), the vertical lobe complex and the optic lobes may be consequences of evolutionary innovation in mollusks, and these lobes are concerned with learning ability. We demonstrated that GAD-positive reactions were most numerous in the tract of the vertical lobe from the superior frontal lobe in Sepioteuthis lessoniana, which corresponds to the MSF tract of octopus. Various researchers have suggested that this tract, which shows a matrix-like organization between the vertical lobe, appears to be analogous to vertebrate brain structures involved in learning and memory (e.g. the hippocampus and cerebellum) (Young 1995), and to insect mushroom bodies (Young \& Boycott 1955, Young 1991, Hochner et al. 2006, Hochner 2010). Among cellular processes, a robust, activitydependent long-term potentiation (LTP) underlying the physiological basis of learning and memory that resembles some aspects of vertebrate LTP is shown in this tract.

Many researchers have described the relationship between the GABAergic system and learning and memory in vertebrates; in invertebrates, including the cricket Acheta domesticus, GABA and GABA receptors are distributed in brain regions that are known to be involved in these processes (Strambi et al. 1998). In the honeybee, the involvement of GABA receptors impaired olfactory learning and memory (El Hassani et al. 2009). Many studies have been conducted on LTP of GABAergic synapses in the hippocampus (Stelzer et al. 1987, Grunze et al. 1996, Mclean et al. 1996, Gaiarsa et al. 2002). From these reports, phylogenetically remote animals with advanced learning ability have acquired similar cellular pro- 
cesses during evolution (Hochner et al. 2003), and the results of the present study suggest that GABA might be involved in learning and memory systems in Sepioteuthis lessoniana.

Possible role of GABA in sociality

Sepioteuthis lessoniana exhibits specific behavioral characteristics (such as wellstructured schools and communication) that suggest sociality (Moynihan \& Rodaniche 1982, Hanlon \& Messenger 1996). Social interaction tests examining the relationship between sociality and the brain induced changes in release and uptake of GABA from the hippocampus in mammals (File et al. 1993). Furthermore, aggression, and possibly other social behaviors, may be particularly prone to regulation through GAD65-mediated GABA synthesis (Stork et al. 2000). Sustková-Fiserová et al. (2009) suggested that the GABAergic system represents an important neuronal substrate for the selective attenuation of anxiety and aggression and that it plays a role in sociable behavior. Reports of relationships between sociality and neuronal mechanisms in invertebrates are scarce. However, the GABAergic elements expressed in the tract between the superior frontal lobe and the vertical lobe may play a role in cognitive behaviors such as social interaction, because there are similarities between the hippocampus of the vertebrate brain and the vertical lobe of the cephalopod brain in which abundant GABAergic elements were detected (Young 1991, Hochner et al. 2003).

\section{Distribution of GABAergic elements in Sepioteuthis lessoniana and Eledone cirrhosa}

In the present study we examined the presence of GABAergic elements in the $S$. lessoniana CNS. A previous study reported the distribution of GABA-like immunolabeling in the brain of octopus E. cirrhosa (Cornwell et al. 1993). The expression of GABA ( $E$. cirrhosa) and GAD (S. lessoniana) within the brain is compared in Table 2. The results of Cornwell et al. (1993) correspond fairly well to the results of the present study, with some differences. The main differences in the distribution of GABAergic elements in the $E$. cirrhosa brain were detected in the vertical lobe com-
Table 2. Expression of GAD-positive cell bodies and fibers within the CNS of Eledone cirrhosa (Cornwell et al. 1993) and Sepiotheuthis essoniana (-: no detected staining; + : sparse positive staining; + : moderate positive staining; +++ : high positive staining, ++++ : extensive positive staining)

\begin{tabular}{|c|c|c|c|}
\hline \multirow[b]{2}{*}{ Brain region } & \multirow{2}{*}{$\begin{array}{l}\text { E. cirrhosa } \\
\text { Fibers }\end{array}$} & \multicolumn{2}{|c|}{ S. lessoniana } \\
\hline & & Cell bodies & Fibers \\
\hline Anterior suboesophageal mass & + & + & ++++ \\
\hline Middle suboesophageal mass & +++ & ++ & ++++ \\
\hline Posterior suboesophageal mass & + & - & ++++ \\
\hline \multicolumn{4}{|l|}{ Supraoesophageal lobes } \\
\hline Superior buccal lobe & ++ & + & \\
\hline Posterior buccal lobe & + & ++ & \\
\hline Inferior frontal lobe & + & - & +++ \\
\hline Subfrontal lobe & - & - & \\
\hline Superior frontal lobe & + & - & +++ \\
\hline Vertical lobe & + & + & ++ \\
\hline Subvertical lobe & + & + & +++ \\
\hline Anterior basal lobe & + & + & \\
\hline Interbasallobes & + & - & \\
\hline Medianbasallobe & + & - & ++ \\
\hline Lateral basal lobes & + & - & \\
\hline Dorsal basal lobe & ++ & ++ & ++ \\
\hline Subpedunculatleobes & + & - & ++ \\
\hline \multicolumn{4}{|l|}{ Optic lobes } \\
\hline Optic lobe: medulla & + & + & +++ \\
\hline Optic lobe: plexiform layer & +++ & - & ++ \\
\hline Pedunclelobe & + & - & \\
\hline Olfactorylobe & + & - & \\
\hline
\end{tabular}

plex and in the anterior and posterior subesophageal masses. GABAergic elements were abundant in the vertical lobe complex of $S$. lessoniana. However, GABA-immunoreactivities in the vertical lobe of $E$. cirrhosa are weak compared with other lobes, particularly in the neuropil layer. Numerous experiments have shown that lesions in the vertical lobe system impair visual discrimination tasks (Young 1961, 1965). Cephalopods possess sophisticated sense organs that enable them to solve complex problems in their environments. Furthermore, GABAergic elements were very abundant in the anterior, middle, and posterior subesophageal masses of the $S$. lessoniana brain concerned with lower and intermediate motor center functions; in the E. cirrhosa brain, these elements are distributed abundantly in restricted regions in the anterior (the pre- and post-brachial lobes, which are concerned with control of the arms) and middle subesophageal mass (the lateral pedal lobes constituting an oculomotor center). The differences in distribution of GABAergic elements between $E$. cirrhosa and $S$. lessoniana may relate to differences in the animals' movements. Cephalopod lifestyles are highly varied. Octopuses are benthic and solitary whereas squids are free-swimming and form schools (Mather 1995). 
Interspecific differences in neural systems might also account for species-specific properties (Kanda et al. 2003, Takuwa-Kuroda et al. 2003). The neuroanatomical differences demonstrated in the present study may be linked to differences in lifestyle.

Acknowledgements. We thank H. Higa for assisting in squid egg collection, and laboratory members for their help in squid rearing. This work was financially supported by a Grant-in-Aid for Scientific Research (C), Project No. 20580207, MEXT to Y.I.

\section{LITERATURE CITED}

Arshavsky YI, Deliagina TG, Gamkrelidze GN, Orlovsky GN, Panchin YV, Popova LB, Shupliakov OV (1993) Pharmacologically induced elements of the hunting and feeding behavior in the pteropod mollusc Clione limacina. I. Effects of GABA. J Neurophysiol 69:512-521

- Bardou I, Maubert E, Leprince J, Chichery R and others (2009) Distribution of oxytocin-like and vasopressin-like immunoreactivities within the central nervous system of the cuttlefish, Sepia officinalis. Cell Tissue Res 336: 249-266

Boycott BB (1961) The functional organization of the brain of the cuttlefish Sepia officinalis. Proc R Soc Lond B Biol Sci 153:503-534

Boycott BB, Young JZ (1950) The comparative study of learning. In: Danielli JF, Brown R (eds) Physiological mechanisms in animal behaviour. Symposia of the Society for Experimental Biology, Vol 4. Academic Press, Oxford, p 432-453

Budelmann BU (1995) The cephalopod nervous system: what evolution has made of the molluscan design. In: Breidbach O, Kutsch W (eds) The nervous system of invertebrates: an evolutionary and comparative approach. Birkhäuser Verlag, Basel p 115-138

Bullock TH, Horridge GA (1965) Structure and function in the nervous system of invertebrates: Vol 1. WH Freeman \& Company, San Francisco, CA

Chichery MP, Chichery R (1987) The anterior basal lobe and control of prey-capture in the cuttlefish (Sepia officinalis). Physiol Behav 40:329-336

Chichery MP, Chichery R (1991) The predatory behaviour of Sepia officinalis; ethological and neurophysiological studies. In: E. Boucaud-Camou (ed) First international symposium on the cuttlefish sepia. La seiche. Centre de Publications de l'Universite de Caen, Caen, p 281-288

$>$ Cooke IRC, Gelperin A (1988) Distribution of GABA-Iike immunoreactive neurons in the slug Limax maximus. Cell Tissue Res 253:77-81

Cournil I, Meyrand P, Moulins M (1990) Identification of all GABA-immunoreactive neurons projecting to the lobster stomatogastric ganglion. J Neurocytol 19:478-493

Cornwell CJ, Messenger JB, Williamson R (1993) Distribution of GABA-like immunoreactivity in the octopus brain. Brain Res 621:353-357

- D'Aniello A, Nardi G, De Santis A, Vetere A and others (1995) Free l-amino acids and d-aspartate content in the nervous system of Cephalopoda. A comparative study. Comp Biochem Physiol B 112:661-666

Díaz-Ríos M, Suess E, Miller MW (1999) Localization of GABA-like immunoreactivity in the central nervous system of Aplysia californica. J Comp Neurol 413:255-270
Dickel L, Chichery MP, Chichery R (1997) Post-embryonic maturation of the vertical lobe complex and early development of predatory behavior in the cuttlefish (Sepia officinalis). Neurobiol Learn Mem 67:150-160

El Hassani AK, Dupuis JP, Gauthier M, Armengaud C (2009) Glutamatergic and GABAergic effects of fipronil on olfactory learning and memory in the honeybee. Invert Neurosci 9:91-100

Elliott CJH, Susswein AJ (2002) Comparative neuroethology of feeding control in mollusks. J Exp Biol 205:877-896

> Ennis M, Aston-Jones G (1989) GABA-mediated inhibition of locus coeruleus from the dorsomedial rostral medulla. J Neurosci 9:2973-2981

> File SE, Zangrossi H, Andrews N (1993) Social interaction and elevated plus-maze tests: changes in release and uptake of 5-HT and GABA. Neuropharmacology 32:217-221

Gaiarsa JL, Caillard O, Ben-Ari Y (2002) Long-term plasticity at GABAergic and glycinergic synapses: mechanisms and functional significance. Trends Neurosci 25:564-570

Grunze HC, Rainnie DG, Hasselmo ME, Barkai E, Hearn EF, McCarley RW, Greene RW (1996) NMDA-dependent modulation of CA1 local circuit inhibition. J Neurosci 16: 2034-2043

Hanlon RT, Messenger JB (1996) Cephalopod behavior. Cambridge University Press, Cambridge

Hatakeyama D, Ito E (2000) Distribution and developmental changes in GABA-like immunoreactive neurons in the central nervous system of pond snail, Lymnaea stagnalis. J Comp Neurol 418:310-322

- Hernádi L (1994) Distribution and anatomy of GABA- like immunoreactive neurons in the central and peripheral nervous system of the snail Helix pomatia. Cell Tissue Res 277:189-198

> Hochner B (2010) Functional and comparative assessments of the octopus learning and memory system. Front Biosci S2:764-771

Hochner B, Brown ER, Langella M, Shomrat T, Fiorito G (2003) A learning and memory area in the octopus brain manifests a vertebrate-like long-term potentiation. J Neurophysiol 90:3547-3554

Hochner B, Shomrat T, Fiorito G (2006) The octopus: a model for a comparative analysis of the evolution of learning and memory mechanisms. Biol Bull 210:308-317

Jackson FR, Newby LM, Kulkarni SJ (1990) Drosophila GABAergic systems: sequence and expression of glutamic acid decarboxylase. J Neurochem 54:1068-1078

Kanda A, Takuwa-Kuroda K, Iwakoshi-Ukena E, Minakata $H$ (2003) Single exon structures of the oxytocin/vasopressin superfamily peptides of octopus. Biochem Biophys Res Commun 309:743-748

> Kobayashi S, Takayama C, Ikeda Y (2013) Ontogeny of the brain in oval squid Sepioteuthis lessoniana (Cephalopoda: Loliginidae) during the post-hatching phase. J Mar Biol Assoc UK 93:1663-1671

Kudo T, Uchigashima M, Miyazaki T, Konno K and others (2012) Three types of neurochemical projection from the bed nucleus of the stria terminalis to the ventral tegmental area in adult mice. J Neurosci 32:18035-18046

> Lee PG, Turk PE, Yang WT, Hanlon RT (1994) Biological characteristics and biomedical applications of the squid Sepioteuthis lessoniana cultured through multiple generations. Biol Bull 186:328-341

> Lunt GG (1991) GABA and GABA receptors in invertebrates. Semin Neurosci 3:251-258

Marthy HJ (1987) Ontogenesis of the nervous system in cephalopods. In: Ali MA (ed) Nervous systems in invertebrates. Springer Verlag, New York, NY, p 443-459 
Mather JA (1995) Cognition in cephalopods. Adv Stud Behav 24:317-353

McLean HA, Caillard O, Khazipov R, Ben-Ari Y, Gaiarsa JL (1996) Spontaneous release of GABA activates GABAB receptors and controls network activity in the neonatal rat hippocampus. J Neurophysiol 76:1036-1046

Meister G (1972) Organogenese von Loligo vulgaris Lam. Zool Jahrb Abt Syst Oekol Geogr Tiere 89:247-300

Messenger JB (1979) The nervous system of Loligo. IV. Philos Trans R Soc Lond B Biol Sci 285:275-309

Messenger JB (1983) Multimodal convergence and the regulation of motor programs in cephalopods. In Horn E (ed) Multimodal convergences in sensory systems. Gustav Fischer, Stuttgart, p 77-98

Messenger JB (1996) Neurotransmitters of cephalopods. Invert Neurosci 2:95-114

Messenger JB (2001) Cephalopod chromatophores: neurobiology and natural history. Biol Rev Camb Philos Soc 76: 473-528

Miczek KA, Fish EW, Bold JF, Almeida RMM (2002) Social and neural determinants of aggressive behavior: pharmacotherapeutic targets at serotonin, dopamine and $\gamma$-aminobutyric acid systems. Psychopharmacology (Berl) 163:434-458

Moynihan M, Rodaniche AF (1982) The behavior and natural history of the Caribbean reef squid Sepioteuthis sepioidea. Adv Ethol 59:1-150

Nishimura K, Kitamura Y, Umesono Y, Takeuchi K, Takata K, Taniguchi T, Agata K (2008) Identification of glutamic acid decarboxylase gene and distribution of GABAergic nervous system in the planarian Dugesia japonica. Neuroscience 153:1103-1114

Nixon M, Young JZ (2003) The brains and lives of cephalopods. Oxford University Press, Oxford

Packard A (1972) Cephalopods and fish: the limits of convergence. Biol Rev Camb Philos Soc 47:241-307

Paxinos G (2004) The rat nervous system. Academic Press, London

Richmond JE, Bulloch AGM, Bauce L, Lukowiak K (1991) Evidence for the presence, synthesis, immunoreactivity, and uptake of GABA in the nervous system of the snail Helisoma trivolvis. J Comp Neurol 307:131-143

Richmond JE, Murphy AD, Lukowiak K, Bulloch AM (1994) GABA regulates the buccal motor output of Helisoma by 2 pharmacologically distinct actions. J Comp Physiol A Neuroethol Sens Neural Behav Physiol 174:593-600

Sanders FK, Young JZ (1940) Learning and other functions of the higher nervous centres of Sepia. J Neurophysiol 3: 501-526

Segawa S (1987) Life history of the oval squid, Sepioteuthis lessoniana, in Kominato and adjacent waters central Honshu, Japan. J Tokyo Univ Fish 74:67-105

Shigeno S, Yamamoto M (2002) Organization of the nervous system in the pygmy cuttlefish, Idiosepius paradoxus Ortmann (Idiosepiidae, Cephalopoda). J Morphol 254:65-80

Shigeno S, Kidokoro H, Thuchiya K, Segawa S, Yamamoto M (2001a) Development of the brain in the oegopsid squid, Todarodes pacificus to juvenile. Zoolog Sci 18:1081-1096

Shigeno S, Tsuchiya K, Segawa S (2001b) Embryonic and paralarval development of the central nervous system of the loliginid squid (Sepioteuthis lessoniana). J Comp Neurol 437:449-475

Shomrat T, Feinstein N, Klein M, Hochner B (2010) Sero-

Editorial responsibility: Roger Villanueva,

Barcelona, Spain tonin is a facilitatory neuromodulator of synaptic transmission and 'reinforces' long-term potentiation induction in the vertical lobe of Octopus vulgaris. Neuroscience 169:52-64

Stelzer A, Slater NT, Ten Bruggencate G (1987) Activation of NMDA receptors blocks GABAergic inhibition in an in vitro model of epilepsy. Nature 326:698-701

Stork O, Ji FY, Kaneko K, Stork S and others (2000) Postnatal development of a GABA deficit and disturbance of neural functions in mice lacking GAD65. Brain Res 865:45-58

Strambi C, Cayre M, Sattelle DB, Augier R, Charpin P, Strambi A (1998) Immunocytochemical mapping of an RDL-Like GABA receptor subunit and of GABA in brain structures related to learning and memory in the cricket Acheta domesticus. Learn Mem 5:78-89

Sugimoto C, Ikeda Y (2012) Ontogeny of schooling behavior in the oval squid Sepioteuthis lessoniana. Fish Sci 78: $287-294$

Sustková-Fiserová M, Vávrová J, Krsiak M (2009) Brain levels of GABA, glutamate and aspartate in sociable, aggressive and timid mice: an in vivo microdialysis study. Neuroendocrinol Lett 30:79-84

Takuwa-Kuroda K, Iwakoshi-Ukena E, Kanda A, Furukawa Y, Matsushima O, Minakata H (2003) Octopus, which owns the most advanced brain in invertebrates, has two members of vasopressin/oxytocin superfamily as in vertebrates. Regul Pept 115:139-149

Tansey EM (1979) Neurotransmitters in the cephalopod brain. Comp Biochem Physiol 64C:173-182

Todd AJ, Spike RC, Price RF, Neilson M (1994) Immunocytochemical evidence that neurotensin is present in glutamatergic neurons in the superficial dorsal horn of the rat. J Neurosci 14:774-784

Tsukada Y, Uemara K, Hirano S, Nagata Y (1964) Distribution of amino acids in the brain in different species. In: Richter D (ed) Comparative neurochemistry. Pergamon, Oxford, p 179-183

> Williamson R, Chrachri A (2004) Cephalopod neural networks. Neurosignals 13:87-98

- Young JZ (1961) Learning and discrimination in the octopus. Biol Rev Camb Philos Soc 36:32-95

> Young JZ (1965) The organization of a memory system. Proc R Soc Lond 163:285-320

Young JZ (1971) The anatomy of the nervous system of Octopus vulgaris. Clarendon, Oxford

Young JZ (1974) The central nervous system of Loligo. I. The optic lobe. Philos Trans R Soc Lond B 267:263-302

Young JZ (1976) The nervous system of Loligo. II. Suboesophageal centres. Philos Trans R Soc Lond B 274:101-167

Young JZ (1977) The nervous system of Loligo III. Higher motor centres: The basal supraoesophageal lobes. Philos Trans R Soc Lond B 276:351-398

Young JZ (1979) The nervous system of Loligo V. The vertical lobe complex. Philos Trans R Soc Lond B 285:311-354

Young JZ (1991) Computation in the learning system of cephalopods. Biol Bull 180:200-208

Young JZ (1995) Multiple matrices in the memory system of octopus. In: Abbott JN, Williamson R, Maddock L (eds) Cephalopod neurobiology. Oxford University Press, Oxford, p 431-443

Young JZ, Boycott BB (1955) Memories controlling attacks on food objects by Octopus vulgaris Lamarck. Pubbl Stn Zool Napoli 27:232-249

Submitted: January 8, 2013; Accepted: July 17, 2013

Proofs received from author(s): September 10, 2013 